RECEBIDO EM 23/05/2014. ACEITO EM 09/11/2014.

\title{
Principios do lean manufacturing aplicados em uma fábrica de injeção de peças plásticas: análise do resultado operacional
}

\section{Jeferson Silveira Pawlak}

Sociedade Educacional de Santa Catarina - UNISOCIESC

jpawlak@bol.com.br

\section{Marcelo Macedo}

Universidade Federal de Santa Catarina - UFSC

marcelomacedo@egc.ufsc.br

\section{RESUMO}

A capacidade de produção de uma empresa pode comprometer a eficiência dos setores clientes subsequentes, o que pode impactar nos resultados da organização. Nesse sentido, este artigo analisa o impacto da implantação dos conceitos do Lean Manufacturing (LM) nos resultados operacionais de uma fábrica de injeção de peças plásticas nos níveis tático e operacional. A pesquisa justifica-se pelo fato de proporcionar condições de aumentar a assertividade na escolha das iniciativas de melhoria a serem implementadas em uma fábrica de injeção de peças plásticas com o objetivo de melhorar seus resultados operacionais. $\mathrm{O}$ estudo em questão está estruturado em três fases: identificação do problema a ser solucionado, implantação dos conceitos do LM em uma família de produtos, e avaliação final do estudo com base no conhecimento adquirido, nos dados coletados durante a implantação do projeto e na comparação dos indicadores de desempenho definidos para os níveis tático e operacional. A partir dos dados apresentados, observa-se que as iniciativas de melhoria da função processo com base nos conceitos do LM foram bem sucedidas.

Palavras-chave: Lean manufacturing; Injeção de peças plásticas; Resultado operacional.

\section{ABSTRACT}

The production capacity of a company may compromise the efficiency of the subsequent client sectors, which may impact the results of the organization. In this sense, this paper analyzes the impact of the implementation of the concepts of Lean Manufacturing (LM) in operating results of factory plastic injection parts at the tactical and operational levels. The research is justified by the fact provide conditions for increasing assertiveness in the choice of improvement initiatives to be implemented in a factory of plastic injection parts in order to improve its operating results. This study is structured in three phases: identifying the problem to be solved, the implementation of concepts of LM in a product family, and final evaluation of the study based on knowledge gained, the data collected during the project implementation and comparison performance indicators defined for the tactical and operational levels. From 
the data presented, it is observed that initiatives to improve the process function based on concepts from LM were successful.

Keywords: Lean manufacturing; Plastic injection; Operational results.

\section{Introdução}

Segundo Paim et al. (2009), a Engenharia de Produção evoluiu até o contexto atual adaptando-se às características econômicas e sociais em que estava inserida. Os quadros conceituais evolutivos, ou ciclos, que fazem parte da essência da Engenharia de Produção são a Administração Científica, o Lean Manufacturing, o Controle da Qualidade Total (TQC), a Reengenharia, a Teoria das Restrições e a Gestão por Processos.

De acordo com Nonaka e Takeuchi (1997), os benefícios de cada ciclo estavam relacionados a fatores como a melhoria das operações, a otimização dos processos através da eliminação dos desperdícios, a incorporação de ferramentas, a sistematização de tarefas para gerir as operações, a melhoria da qualidade dos produtos e serviços, o redesenho e a estabilização dos processos.

Para Nonaka e Takeuchi (1997), o cenário atual, caracterizado pela importância estratégica da informação e do conhecimento, exige que as organizações busquem a sua sobrevivência a longo prazo, através da combinação das práticas de sucesso do passado com a inovação que irá gerar resultados significativos para os chamados stakeholders ou partes interessadas.

Para Paim et al. (2009), o estudo realizado pelos principais fundadores da Toyota, os senhores Toyodo Sakichi, Taiichi Ohno e Shigeo Shingo, para combater os desperdícios, deu origem a um conjunto de princípios e técnicas, como por exemplo: a autonomação, o Kanban, a troca rápida de ferramentas, os dispositivos antifalha (poka yoke), o desdobramento da função qualidade (QFD), os arranjos físicos celulares, a análise de valor, a manutenção produtiva total, entre outras práticas, que passaram a compor a filosofia de produção conhecida como just in time (JIT).

Nesse sentido, esta pesquisa tem como objetivo a análise do impacto da implantação dos princípios do LM em uma família de produtos de uma fábrica de injeção de peças plásticas.

\section{Implantação dos conceitos do LM em uma família de produtos de uma fábrica de injeção de peças plásticas}

A implantação dos conceitos do LM na família de produtos tem como objetivo aumentar a produtividade em função da redução das perdas que existem nas interfaces dos processos, classificadas por Shingo (1996) em sete categorias: perdas por processamento, transporte, estoque, movimentação, superprodução, espera e defeitos. Ou seja, o foco será atuar na função processo, a fim de melhorar o fluxo de materiais e de informações nas etapas de planejamento da produção, injeção das peças plásticas, montagem e embalagem dos produtos fabricados.

No nível operacional, o sucesso desta iniciativa será mensurado pelo indicador de OEE, que é a multiplicação dos índices de qualidade, disponibilidade e desempenho. Esperase que a implantação dos conceitos e práticas do LM melhore o indicador de OEE e, consequentemente, influenciem positivamente o indicador do nível tático, que é a quantidade de produtos vendidos, mas não disponíveis para a entrega.

\subsection{Mapeamento do fluxo de valor}

Para compreender o fluxo de materiais, informações e planejamento da família de produtos, elaborou-se o mapa de fluxo de valor para um produto desta família. O mapeamento 
permitiu a fácil visualização dos desperdícios ao longo da cadeia de produção, desde a programação da produção até a disposição dos produtos acabados para o estoque.

A figura 1 representa o mapa de fluxo de valor do estado atual deste produto.

Figura 1 - Mapa da situação atual

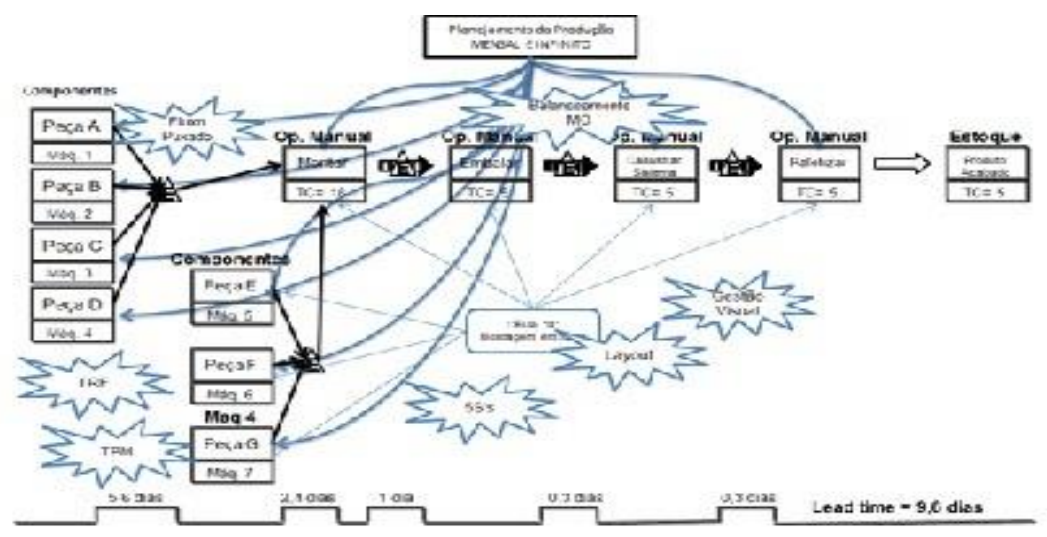

Fonte: Fabrica de injeção de peças plásticas.

As práticas e as técnicas do LM implementadas na família de produtos podem ser identificadas pela cor azul no mapa de fluxo de valor.

\subsection{Redes de fábricas focalizadas (minifábricas)}

Pelo fato de ser complexa a administração de uma grande instalação, optou-se por separar a fábrica de injeção em 4 famílias de produtos e as famílias de produtos em processos comuns dedicados, sendo os processos divididos em dois grupos:

a) Processos puxadores: são responsáveis pela injeção da peça na qual os componentes serão montados; geralmente é a peça de maior dimensão do conjunto montado.

b) Injeção de componentes: fabricação das peças a serem utilizadas no componente puxador.

Cada minifábrica no interior da fábrica é autônoma em seus processos produtivos, administrativos e de informação, tendo uma estrutura hierárquica capaz de decidir sobre as questões relacionadas ao planejamento da produção, solicitação de insumos, sequenciamento, produção, qualidade e manutenção.

\subsection{Máquinas simples e dedicadas}

As máquinas utilizadas para a produção das peças plásticas são injetoras de baixa complexidade, fáceis de absorver variações de demanda, pois, ao trocar o molde, muda-se o produto produzido, sendo necessária a otimização dos tempos de setup para viabilizar a produção de pequenos lotes de produtos diferentes.

Para identificar os processos comuns, a fim de dedicar as injetoras para produtos específicos, foram utilizados mapas de processo. A figura 2 representa esta etapa do trabalho. 
Figura 2 - Mapa do processo

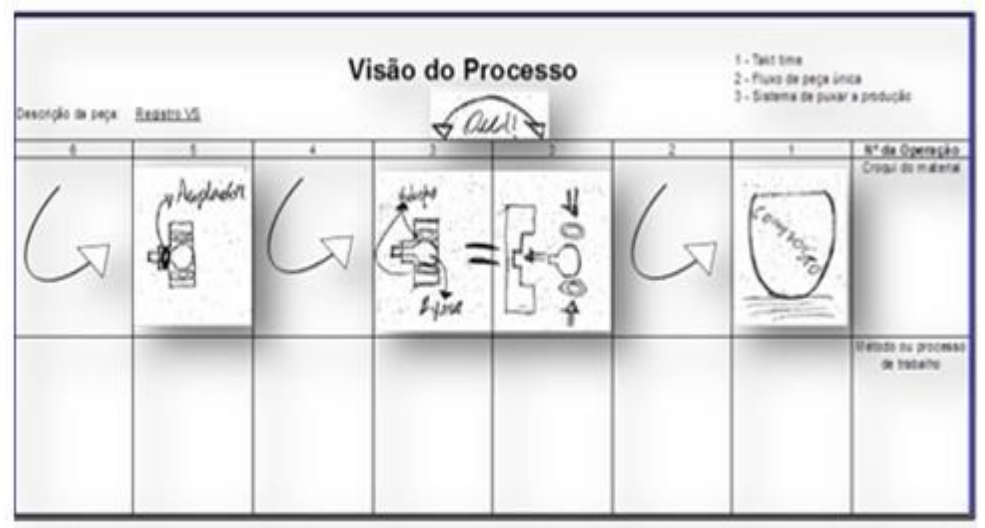

Fonte: Fabrica de injeção de peças plásticas.

\subsection{Arranjo físico celular}

A etapa seguinte consistiu em rever o arranjo físico, a fim de viabilizar as células de manufatura em formato de "U", que são geralmente utilizadas para linhas mais curtas e possibilitam a implantação do conceito de fluxo unitário de uma peça, onde o produto movimenta-se pelo processo, um de cada vez, sem interrupções e estoques, ao ritmo determinado pela demanda dos clientes. Para viabilizar esta análise, foram utilizadas figuras em escala, recortadas em papel e coladas sobre uma folha quadriculada, conforme a figura 3.

Figura 3 - Definição dos arranjos físicos celulares

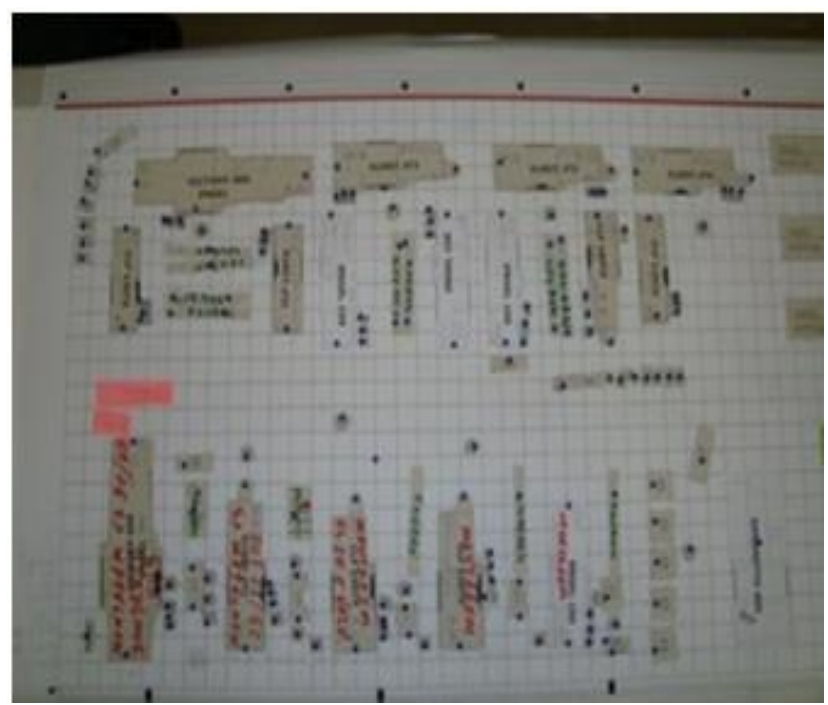

Fonte: Fabrica de injeção de peças plásticas.

\subsection{Manutenção produtiva total}

Para reduzir os tempos de espera, ocasionados pelas quebras não previstas, optou-se por implantar os conceitos de manutenção produtiva total nos moldes utilizados pela família de produtos, pois as interrupções do fluxo produtivo por problemas nos moldes representavam, em 2011, 55\% do total das perdas de responsabilidade da manutenção, conforme mostra o gráfico 1 . 
Gráfico 1 - Pareto das perdas de manutenção

Distribuiçẵo dos motivos das perdas por manutençẳo 2011 Injeção COJ (horas)

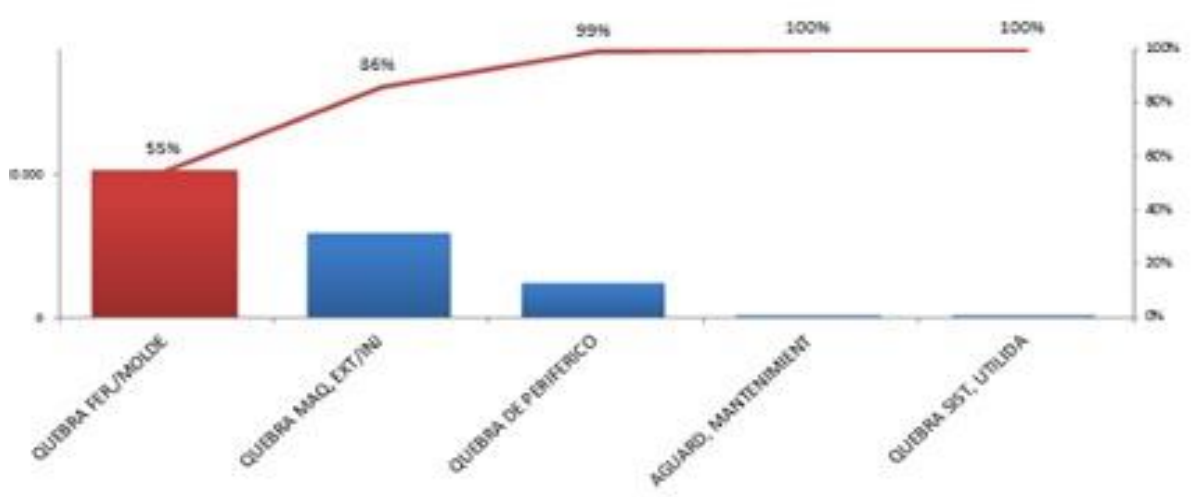

Fonte: Fabrica de injeção de peças plásticas.

A iniciativa consiste em restaurar as condições nominais dos moldes críticos e estabelecer uma rotina de verificação e correção preventiva, realizada por uma equipe específica antes (preparação) e após (triagem) a produção de um lote de peças.

A figura 4 é uma foto da equipe e da área dedicada a esta tarefa na família de produtos.

Figura 4 - Área de triagem e preparação de moldes

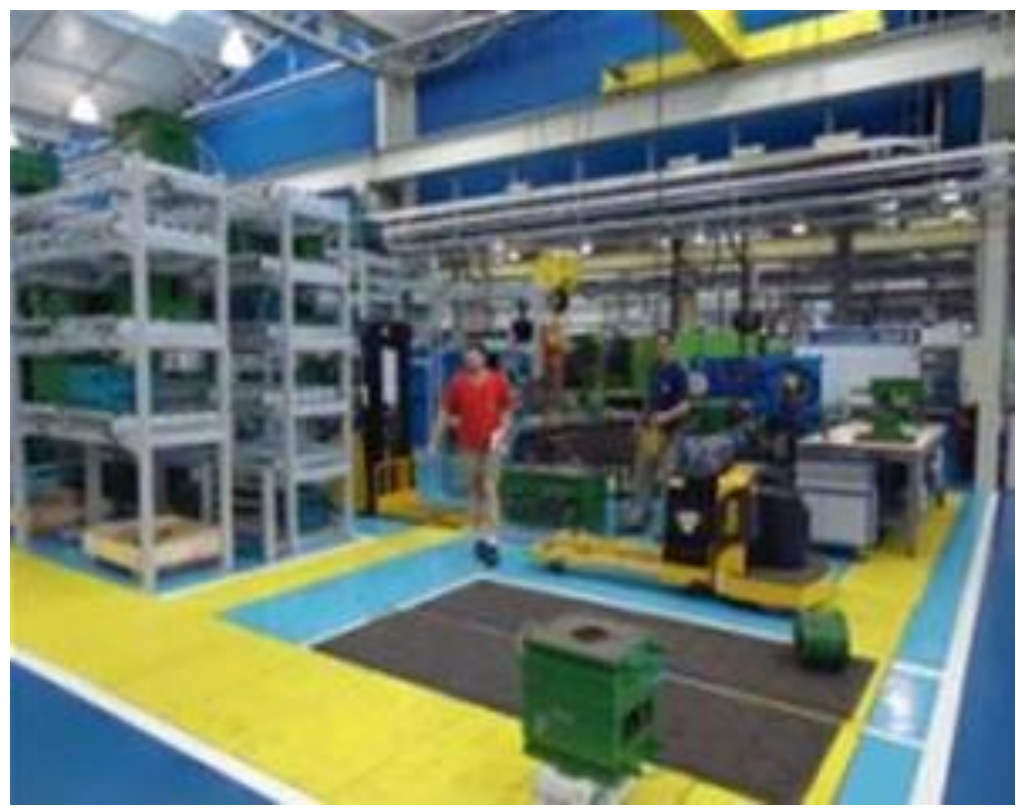

Fonte: Fabrica de injeção de peças plásticas.

\subsection{Troca rápida de ferramentas}

A redução do tempo de espera para a troca de ferramentas pode viabilizar a diminuição dos lotes de produção, aproximando o fluxo de produção ao lote unitário de peças.

As iniciativas para otimizar o tempo de troca das ferramentas concentraram-se em identificar as operações que são realizadas com a máquina parada, conhecidas como setup interno, e com a máquina em funcionamento, o setup externo. Através do acompanhamento de uma amostragem, observou-se que o setup interno era composto por três grandes tempos (atividades): 
a) Realização da troca do molde por uma equipe de profissionais especializados e dedicados a esta tarefa, chamados de trocadores;

b) Tempo de espera (lacuna de tempo) entre o fim das tarefas realizadas pelos trocadores e o início da parametrização da injetora, para iniciar a produção das peças do novo lote de produção, realizado por outra equipe, chamada de equipe de "setapeiros";

c) Parametrização da injetora e início de produção do novo lote de peças.

A figura 5 representa a composição dos tempos para a troca de ferramentas.

Figura 5 - Composição dos tempos para troca de ferramentas

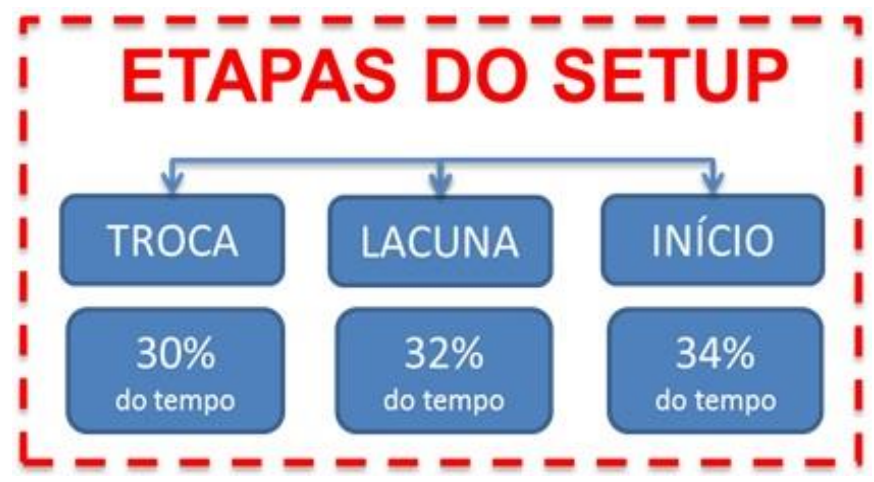

Fonte: Fabrica de injeção de peças plásticas.

Após a identificação dos tempos que compõem a troca das ferramentas, as ações foram concentradas em reduzir a lacuna de tempo entre o fim da atividade de troca e a de início de produção.

Para viabilizar a redução, foi implantado um sistema de gestão visual para a programação e o sequenciamento da troca, a fim de não haver trocas simultâneas e de melhorar o fluxo de informações entre as equipes de troca e de início.

A figura 6 é uma foto do quadro de programação das trocas de moldes.

Figura 6 - Sequenciamento das trocas de ferramentas

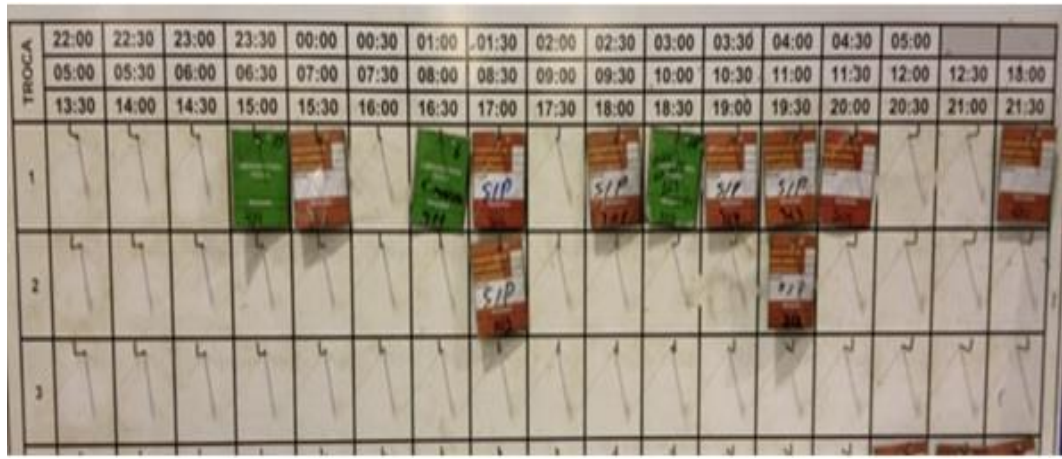

Fonte: Fabrica de injeção de peças plásticas.

\subsection{Kanban}

Para a programação da produção de componentes, foi implantado um sistema Kanban de um cartão. O Kanban foi necessário, pois a maioria das injetoras que produzem componentes são compartilhadas. O Kanban serve para coordenar a produção puxada, levando-se em conta que as peças devem ser retiradas do supermercado e produzidas no momento exato em que são solicitadas pelos cartões. A figura 7 é um dos supermercados de componentes controlados pelo sistema Kanban da família de produtos. 
Figura 7 - Supermercado controlado pelo sistema Kanban

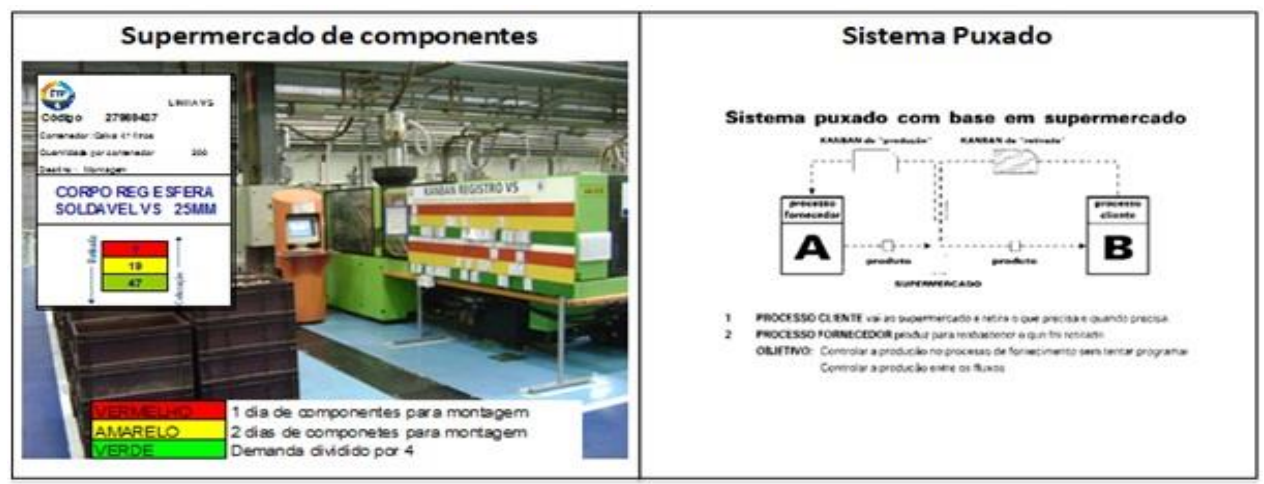

Fonte: Fabrica de injeção de peças plásticas.

\subsection{Nivelamento da produção}

A programação da produção para os processos puxadores foi alterada de um período de 30 dias com visão de capacidade infinita, para um período de dez dias com capacidade finita, levando-se em consideração os recursos disponíveis e a produtividade individual dos equipamentos.

Essa programação teve o objetivo de alcançar um mix de produção que reduza os estoques de determinados itens, ao mesmo tempo em que aumente a flexibilidade do sistema, para atender às variações de demanda dos clientes, ao longo do mês.

Além disso, como ilustra a figura 8, implantou-se o sequenciamento da produção, utilizando-se quadros heijunka para racionalizar a utilização da mão de obra.

Figura 8 - Quadro para nivelamento da produção (heijunkabox)

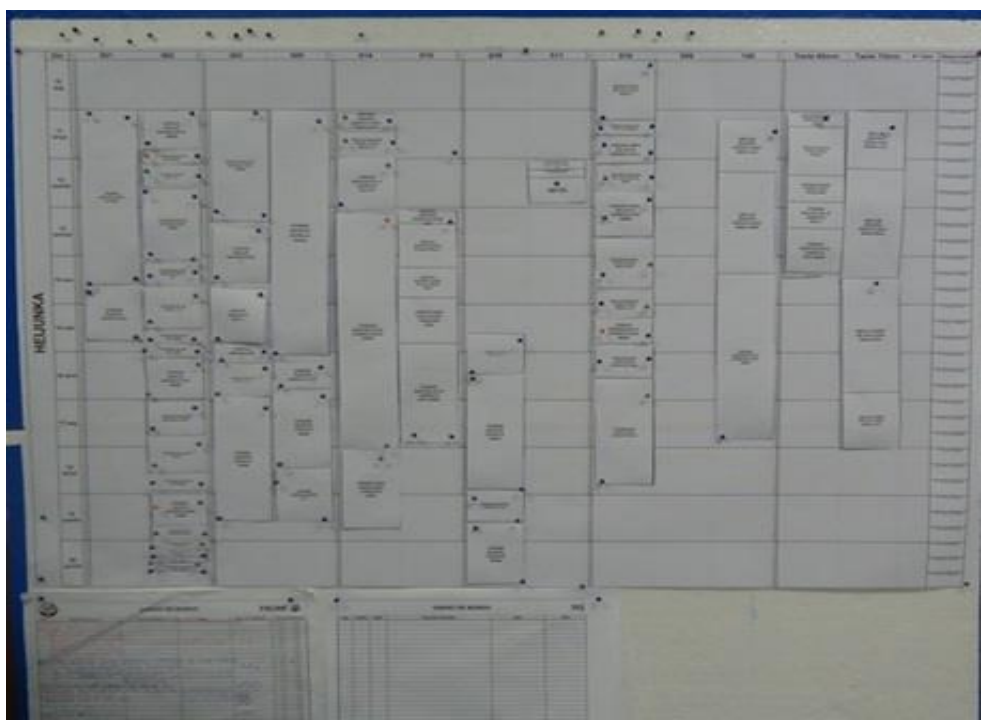

Fonte: Fabrica de injeção de peças plásticas. 
Os projetos de melhoria, os procedimentos operacionais, os indicadores de desempenho e a matriz de habilidade foram colocados em quadros de gestão, de forma a que todos possam facilmente identificar, acompanhar e compreender a direção dos esforços de melhoria.

Na figura 9, é possível visualizar um procedimento operacional padrão, utilizado em um processo de montagem da família de produtos e uma matriz de habilidade.

Figura 9 - Procedimento operacional padrão e matriz de habilidade

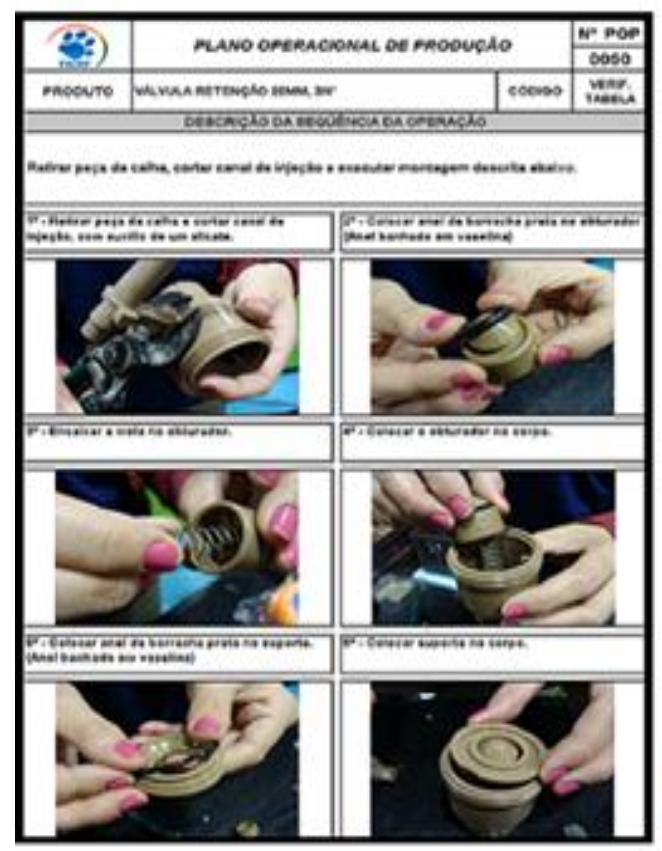

Quadro de gestão de mão de obra com as habilidades de cada operador direcionando onde este pode trabalhar .

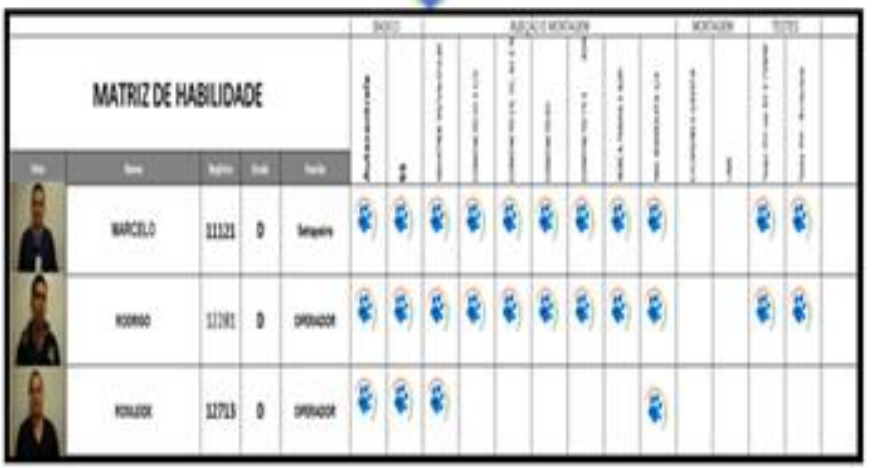

POP's nos produtos montados, operador trabalha somente onde teve treinamento.

Fonte: Fabrica de injeção de peças plásticas.

\section{Resultados alcançados com a implantação do LM na família de produtos}

O indicador de desempenho, voltado ao sistema produtivo, utilizado para medir o sucesso das iniciativas do LM no nível operacional da família de produtos da fábrica de injeção de peças plásticas, foi o OEE (overall equipment effectiveness). Este indicador é calculado pela multiplicação dos índices de qualidade, disponibilidade e eficiência, pois o objetivo é mensurar a eliminação dos desperdícios da função processo, que, de acordo com Shingo (1996), é o foco das iniciativas do LM.

Em função das restrições do compartilhamento das informações da fábrica de injeção de peças plásticas, o indicador de OEE é exposto no gráfico 1 em percentual de evolução, tendo como referencial o resultado praticado no mês de janeiro de 2012. 


\section{Evolução OEE em relação à Jan/12 - Família 2 (\%)}

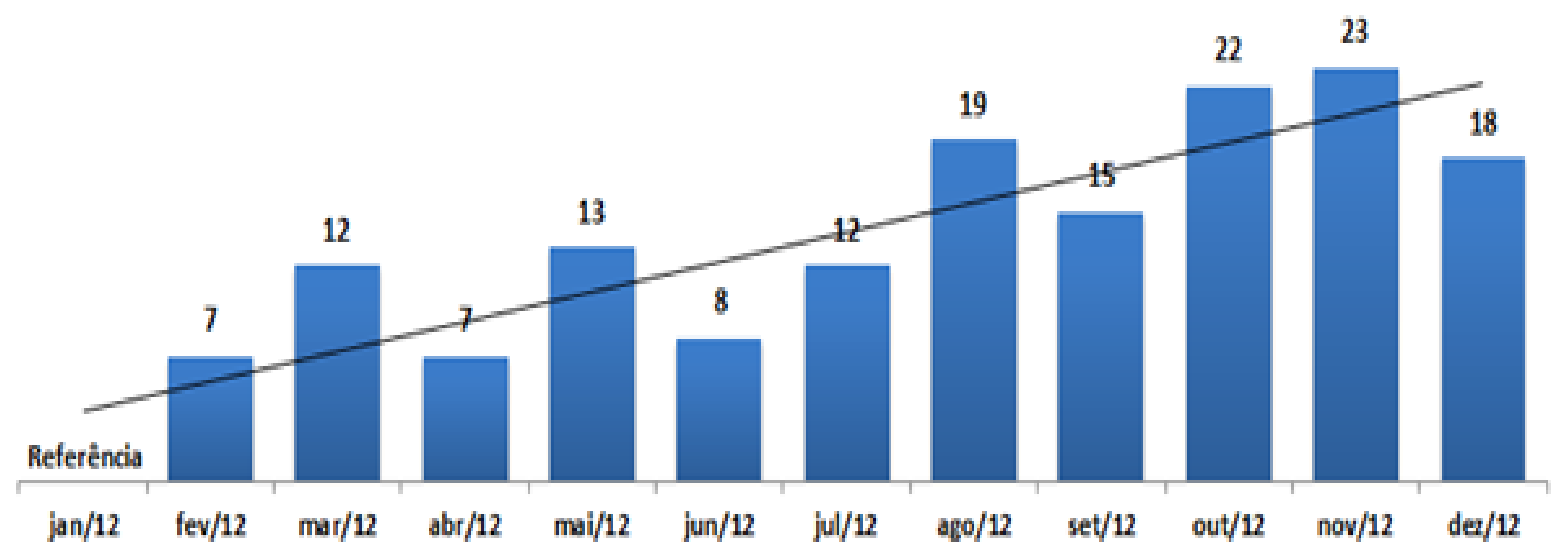

Fonte: Fabrica de injeção de peças plásticas.

Observa-se que as iniciativas de melhoria implantadas impactaram significativamente na produtividade das injetoras de peças plásticas da família de produtos. Comparando-se o mês de janeiro com o de dezembro de 2012, pode-se afirmar que a capacidade nominal de produção da minifábrica de injeção de peças plásticas aumentou em 18 pontos percentuais.

Não foi possível mensurar o impacto individual de cada ferramenta, ou prática do LM, ao longo dos meses de 2012, pois para esta família, as iniciativas foram implantadas em um único estágio ao final do ano de 2011, pois foi construída uma nova área fabril, para a qual as injetoras de peças plásticas foram transferidas e os novos conceitos de produção adotados.

A melhoria do indicador de OEE foi atribuída à maturidade da equipe para trabalhar com o novo sistema produtivo.

Comparando-se a capacidade nominal com as horas necessárias e produtivas desta família no período de janeiro a dezembro, observou-se a evolução do desempenho, em função de as horas produtivas superarem as horas necessárias a partir do mês de agosto de 2012, conforme pode ser visto no gráfico 2 .

Gráfico 2 - Comparativo de desempenho da família de produtos

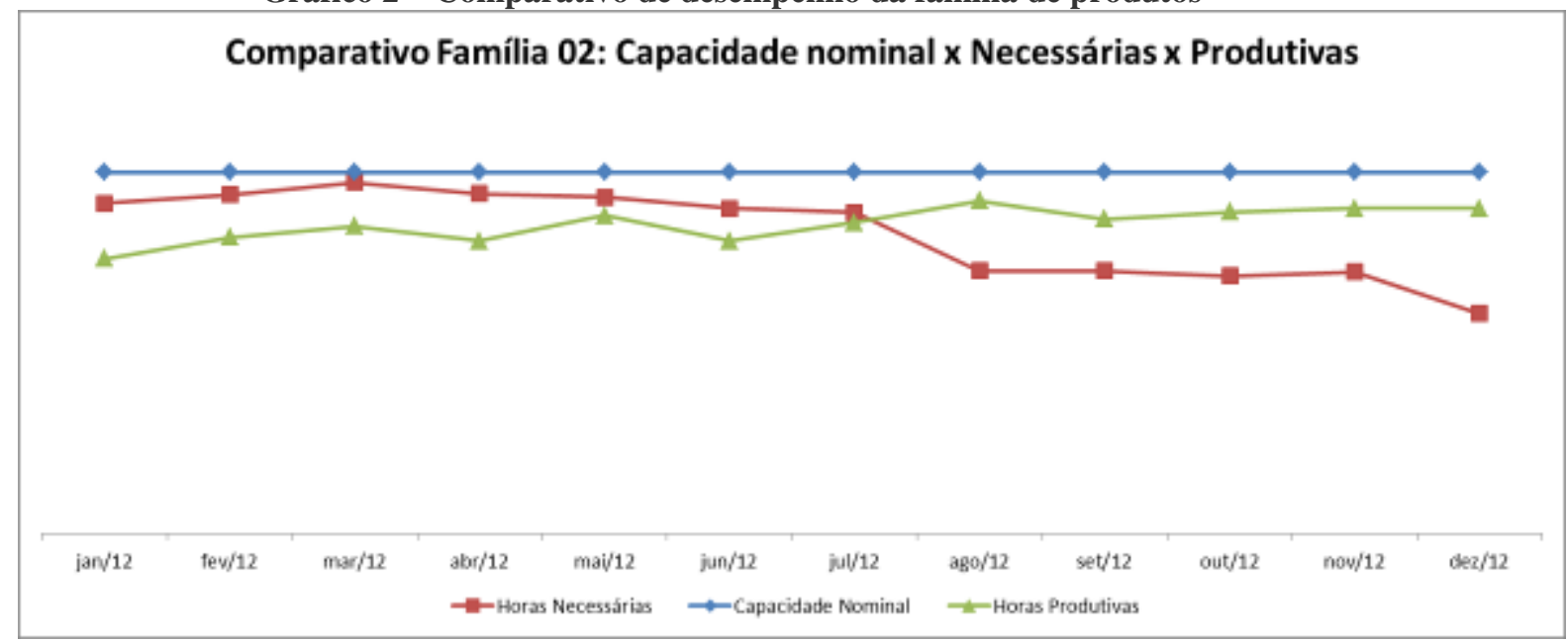

Fonte: Fabrica de injeção de peças plásticas. 
O fato de as horas produtivas terem superado as horas necessárias impactou positivamente na quantidade de produtos vendidos, mas não disponíveis para a venda, conforme mostra o gráfico 3 .

Gráfico 3 - Quantidade de produtos vendidos, mas não disponíveis para entrega

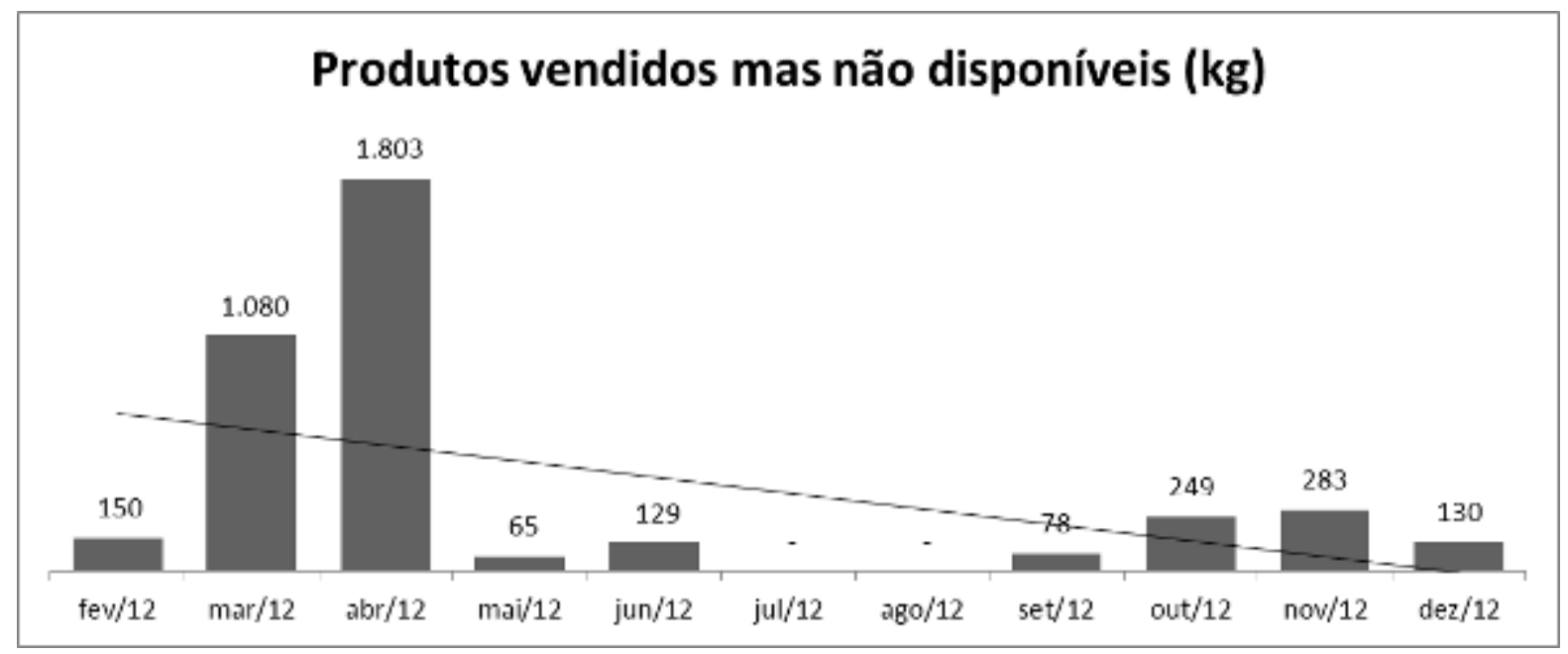

Fonte: Fabrica de injeção de peças plásticas.

O desempenho do indicador de atendimento ao plano de produção (horas produtivas) da família de produtos justifica-se em função da diminuição das horas improdutivas. Comparando-se o desempenho de fevereiro ao do mês de dezembro de 2012, a redução das paradas apresentaram uma evolução significativa, sendo os principais ganhos, representados pelo gráfico 4.

Gráfico 4 - Redução das horas improdutivas da família de produtos

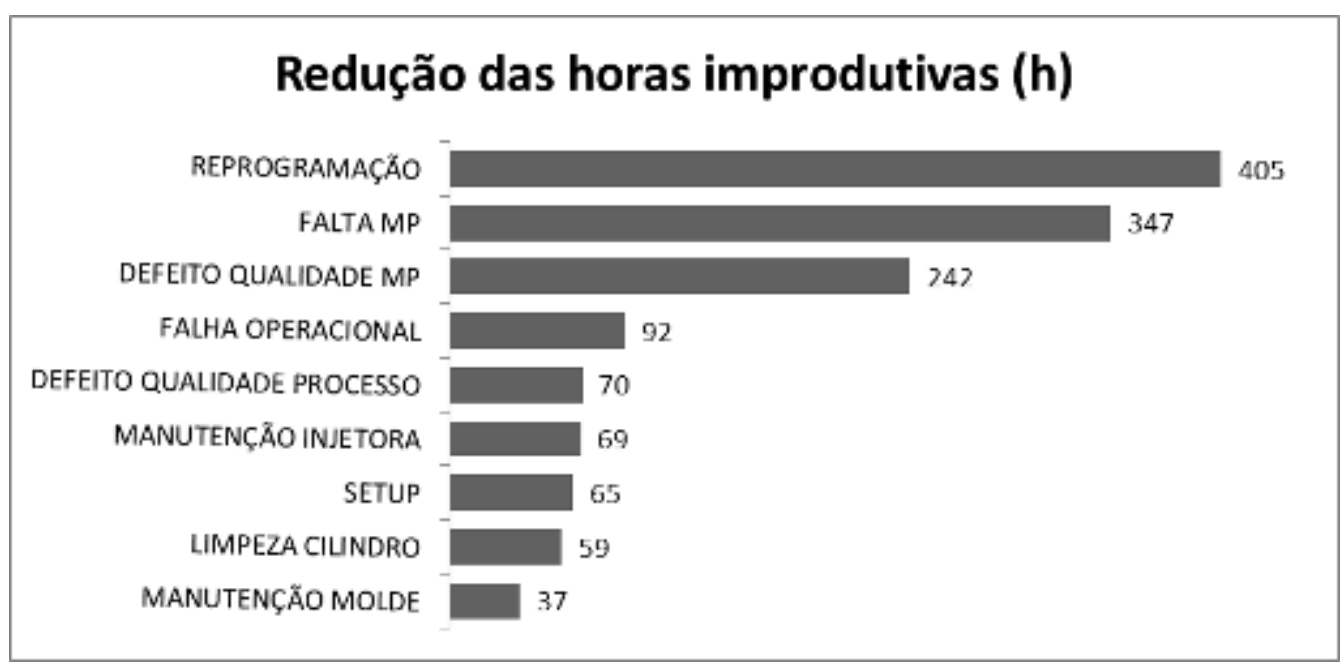

Fonte: Fabrica de injeção de peças plásticas.

A partir dos dados apresentados no decorrer deste trabalho, observa-se que as iniciativas de melhoria da função processo com base nos conceitos do LM foram bem sucedidas quando comparados os indicadores do nível tático e operacional. 
Uma baixa eficiência na função operação e, ou na função processo pode acarretar na falta de capacidade de produção, o que pode comprometer não somente a eficiência das manufaturas, como também dos setores clientes subsequentes, e impactar nos resultados globais da organização. Nesse sentido, a questão que norteou esta pesquisa foi: Como a aplicação de princípios do Lean Manufacturing pode impactar nos resultados operacionais de uma fábrica de injeção de peças plásticas?

Para analisar o impacto da aplicação dos princípios do Lean Manufacturing nos resultados operacionais de uma fábrica de injeção de peças plásticas, definiu-se indicadores, voltados aos sistemas produtivos, que mensuram o impacto das iniciativas do LM nos resultados operacionais.

Os indicadores, voltados aos sistemas produtivos, utilizados no nível tático para a família de produtos foram o atendimento ao plano de produção e a quantidade de produtos vendidos, mas não disponíveis para entrega.

Para o nível operacional da família de produtos, à qual foram implantados os conceitos do LM, o indicador de desempenho foi o OEE, ou seja, a multiplicação dos índices de qualidade, desempenho e disponibilidade do grupo de injetoras que fazem parte dessa família.

Observou-se que as iniciativas de melhoria da função processo com base nos conceitos do LM foram bem sucedidas quando comparados os indicadores do nível tático e operacional.

Portanto, este trabalho pode ajudar a empresa a verificar a ocorrência de desvios entre os resultados operacionais pré-estabelecidos e os resultados alcançados, além de viabilizar a busca da melhoria contínua dos seus processos a partir da ciência, com a finalidade de formular recomendações para o alcance das metas de produção.

Como recomendação para trabalhos futuros, sugere-se a aplicação dos conceitos do LM nas demais famílias de produtos da fábrica de injeção de peças plásticas.

\section{Referências}

ANTUNES JÚNIOR, J. A. V. Em direção a uma teoria geral da administração da produção: uma discussão sobre a possibilidade de unificação da teoria das restrições e da teoria que sustenta a construção dos sistemas de produção com estoque zero. Tese (Doutorado em Administração) - Programa de Pós-Graduação em Administração, Universidade Federal do Rio Grande do Sul, Porto Alegre, 1998.

ANTUNES JÚNIOR, J. A. V.; ALVAREZ, R.; PELLEGRIN, I; KLIPPEL, M.; BORTOLOTTO, P. Sistemas de produção: conceitos e práticas para projeto e gestão da produção enxuta. Porto Alegre: Bookman, 2008.

CAMPOS, Vicente. Gerenciamento da rotina do trabalho do dia a dia. 8. Ed. INDG Tecs, 2004.

CAMPOS, Vicente. O verdadeiro poder. INDG Tecs, 2009.

DAVIS, M.; AQUILANO, N.; CHASE, R. Fundamentos da administração da produção. Tradução de Eduardo D'Agord Schaan e outros. 3. ed. Porto Alegre: Bookman, 2001.

DEON, Agostinho M. Medição do custo das perdas associadas ao processo produtivo de fabricação de celulose e papel. Dissertação (Mestrado em Engenharia 
de Produção) - Programa de Pós-Graduação em Engenharia de Produção,

Universidade Federal de Santa Catarina. Florianópolis, 2001.

FERNANDES, Djair Roberto. Uma contribuição sobre a construção de indicadores e sua importância para a gestão empresarial. Revista da FAE, v.7, n.1, p. 1-18. Curitiba, 2004

GHINATO, P. Sistema Toyota de Produção: mais do que simplesmente just in time. 1 ed., Belo Horizonte, Revista Produção On Line. 1995. Disponível em <scielo.br>..

HARRINGTON, H. J. Aperfeiçoando processos empresariais. São Paulo: Makron Books, 1993.

HRONEC, S. M. Sinais vitais. São Paulo: Makron Books,1994.

KAPLAN, R. S.; NORTON, D. P. A estratégia em ação. Rio de Janeiro: Campus, 1997.

MARTINS, P.; LAUGENI, P. Administração da produção. 2. ed. São Paulo: Saraiva, 2006.

MEYERS, Fred; STEWART, Jim R. Motion and time study for lean manufacturing. 2. ed. New Jersey: Prentice-hall, Inc., 1999.

NAKAJIMA, S. Introdução ao TPM - Total Productive Maintenance. São Paulo: Bookman, 1989.

NONAKA, Ikujiro; TAKEUCHI, Hirotaka. Criação de conhecimento na empresa: como as empresas japonesas geram a dinâmica da inovação. Rio de Janeiro: Campos 1997.

OHNO, T. O sistema Toyota de produção: além da produção em larga escala. Bookman Editora: Porto Alegre, 1997.

PAIM, R. et al. Gestão de processos: pensar, agir e aprender. Porto Alegre: Bookman, 2009.

POSSAMAI, O.; HANSEN, P. B. Indicadores de desempenho gerencial. Florianópolis: PPGEP UFRGS/UFSC, 1998.

REIFSCHNEIDER, Marina Becker. Considerações sobre avaliação de desempenho. Ensaio: aval. Pol. Públ. Educ., Rio de Janeiro, v. 16, n. 58, Mar. 2008. Disponível em: <www.scielo.br>. Acesso em: 22 out. 2012.

REIS, Tathiana. Aplicação da mentalidade enxuta no fluxo de negócios da construção civil a partir do mapeamento do fluxo de valor: estudos de caso. Dissertação (Mestrado em Engenharia Civil) - Faculdade de Engenharia Civil, Arquitetura e Urbanismo, Universidade Estadual de Campinas, Campinas (SP), 2004. 
ROTHER, M.; HARRIS, R. Criando fluxo contínuo: um guia de ação para gerentes, engenheiros e associados da produção. São Paulo: Lean Institute Brasil, 2002.

RUMMLER, G. A.; BRACHE, A. P. Melhores desempenhos das empresas. São Paulo: Makron Books, 1992.

SELLITTO, M. A.; WALTER, C. Medição e pré-controle do desempenho de um plano de ações estratégicas em manufatura. Gestão \& Produção, v. 12, n. 3, p. 443458, 2005 [on-line]. Disponível em: <www.scielo.br>. Acesso em: 23 out. 2012.

SHINGO, Shigeo. Sistemas de produção com estoque zero. Porto Alegre, Bookman, 1996.

SHINGO, Shigeo. O sistema Toyota de produção. Porto Alegre, Bookman, 1996.

SHOOK, J.; ROTHER, M. Aprendendo a enxergar. São Paulo: Lean Institute, 2003.

SLACK, N.; CHAMBERS, S.; JOHNSTON, R. Administração da produção. 2. Ed. São Paulo: Atlas, 2008.

SPEAR, W.; BOWEN, H. Decoding of the DNA the Toyota production system. Harvard Business Review, set./out. 1999.

TUBINO, D. F. Manual de planejamento de controle da produção. 2. ed. São Paulo: Atlas, 2000.

WOMACK, J. P.; JONES, D. T. A máquina que mudou o mundo. 3. ed. Rio de Janeiro: Campus, 1992.

WOMACK, J. P.; JONES, D. T. A mentalidade enxuta nas empresas: lean thinking. 5. ed. Rio de Janeiro: Campus, 2004. 